\title{
UK built Ebola treatment centre opens in Sierra Leone
}

\author{
Anne Gulland
}

London

An 80 bed treatment centre for patients with Ebola virus disease, built by British army engineers and managed by charity Save the Children, has opened in Sierra Leone.

The centre took eight weeks to build and was the first of six British built treatment facilities to open in Sierra Leone. The centre also houses a 12 bed facility for healthcare workers and international workers affected by the disease, which will expand to 20 beds within two months. The centre, in Kerry Town, also has a laboratory run by staff from Public Health England.

Justine Greening, UK secretary of state for international development, paid tribute to Save the Children and the "heroic British medics, Sierra Leonean health workers, and international volunteers whose work in this facility has the potential to save countless lives."

The World Health Organization's latest situation report, dated 5 November, said that Sierra Leone had just 294 beds for Ebola patients. Greening said, "Patients are being turned away from hospitals, reducing their chance of survival, and allowing the disease to spread."

Save the Children is recruiting 200 staff to run the treatment centre, which will start running at a limited capacity initially. The majority of staff will be local, supplemented by expert international staff on short term rotations of four to eight weeks. A further 50 to 70 non-clinical staff and about 100 hygienists will work at the centre.

Construction has begun on the other UK built treatment centres at Port Loko, Makeni, Moyamba, and two in the capital, Freetown. The centres will eventually provide 700 beds and treat up to 8800 patients. A spokeswoman for the UK Department for International Development said that the details on staffing were still being worked out.

The latest WHO report said that there have been 13042 cases of Ebola globally, including 4818 deaths. It said that transmission was stable in Guinea and appeared to be declining in Liberia at a national level, although there were a high number of cases in certain areas. But transmission was "very concerning" in Sierra Leone, with the country reporting 435 confirmed cases in the preceding week.

It said that in the three worst affected countries only 1047 of the 4707 beds planned by the United Nations Ebola response mission were currently in operation - an improvement on the 284 beds in operation at the beginning of August. "The establishment of more beds is in part held back by challenges in finding sufficient numbers of foreign medical teams to operate Ebola treatment centres," the report said.

Two foreign medical teams are currently operating centres in Guinea, and at least five more are needed to operate 350 more beds. Liberia has three foreign medical teams and is in need of 13 more to support the operation of 1200 more beds. Sierra Leone has five teams, and 10 more are being deployed.

Armand Sprecher, a public health specialist at non-governmental organisation Médecins Sans Frontières, told a press conference held on 5 November at the American Society of Tropical Medicine and Hygiene's annual conference in Louisiana that one of the biggest challenges was providing guidance to the new aid organisations arriving in west Africa. "Because of the arrival of new partners in the field we have a lot of people to work with who want to respond, who want guidance, assistance, and training in getting up to speed ... and that is stretching us even further," he said.

Sprecher said that the organisation was trying to measure the number of people dying from conditions other than Ebola. "It's probably much larger than the number of people dying from Ebola right now," he said.

Access all of The BMSs content on the ongoing Ebola outbreak at thebmi.com/ebola.

Cite this as: BMJ 2014;349:96704

๑ BMJ Publishing Group Ltd 2014 